\title{
Eight-Fold Interpenetrating Diamondoid Coordination Polymers for Sensing Volatile Organic Compounds and Metal Ions
}

\author{
Venkatesan Lakshmanan ${ }^{1}$, Yi-Ting Lai ${ }^{1}$, Xiang-Kai Yang ${ }^{1}{ }^{\mathbb{D}}$, Manivannan Govindaraj ${ }^{1}$ (D), Chia-Her Lin ${ }^{2, *}{ }^{\mathbb{D}}$ \\ and Jhy-Der Chen ${ }^{1, *(1)}$
}

1 Department of Chemistry, Chung-Yuan Christian University, Chung Li 32023, Taiwan; venkatesanflower95@gmail.com (V.L.); e0912583362@gmail.com (Y.-T.L.); xiangkaishulin@gmail.com (X.-K.Y.); manivannanjent@gmail.com (M.G.)

2 Department of Chemistry, National Taiwan Normal University, Taipei 11677, Taiwan

* Correspondence: chiaher@ntnu.edu.tw (C.-H.L.); jdchen@cycu.edu.tw (J.-D.C.); Tel.: +886-3-265-3351 (J.-D.C.)

check for
updates

Citation: Lakshmanan, V.; Lai, Y.-T.;

Yang, X.-K.; Govindaraj, M.; Lin,

C.-H.; Chen, J.-D. Eight-Fold

Interpenetrating Diamondoid

Coordination Polymers for Sensing Volatile Organic Compounds and Metal Ions. Polymers 2021, 13, 3018. https://doi.org/10.3390/

polym13183018

Academic Editor: Piotr Dobrzynski

Received: 2 August 2021

Accepted: 5 September 2021

Published: 7 September 2021

Publisher's Note: MDPI stays neutral with regard to jurisdictional claims in published maps and institutional affiliations.

Copyright: (c) 2021 by the authors. Licensee MDPI, Basel, Switzerland. This article is an open access article distributed under the terms and conditions of the Creative Commons Attribution (CC BY) license (https:/ / creativecommons.org/licenses/by/ $4.0 /)$.

\begin{abstract}
Reactions of divalent metal salts with 4,4-oxybis(N-(pyridine-4-yl)-benzamide), $\mathrm{L}$, and naphthalene-1,4-dicarboxylic acid $\left(1,4-\mathrm{H}_{2} \mathrm{NDC}\right)$ in various solvents gave $\left[\mathrm{Zn}(\mathrm{L})(1,4-\mathrm{NDC}) \cdot \mathrm{H}_{2} \mathrm{O}\right]_{\mathrm{n}}$ 1, $\left[\mathrm{Cd}(\mathbf{L})(1,4-\mathrm{NDC})\left(\mathrm{H}_{2} \mathrm{O}\right) \cdot \mathrm{MeOH}\right]_{n}, \mathbf{2}$, and $\left[\mathrm{Co}(\mathrm{L})(1,4-\mathrm{NDC})\left(\mathrm{H}_{2} \mathrm{O}\right)_{0.5} \cdot \mathrm{MeOH}\right]_{n}, \mathbf{3}$, which have been structurally characterized. Complexes 1-3 show eight-fold interpenetrating frameworks with the dia topology, which exhibit porosities substantiated by $\mathrm{CO}_{2}$ adsorption, whereas $\mathbf{1}$ and $\mathbf{2}$ manifest stability in aqueous environments and show high selectivity toward sensing of mesitylene molecules and $\mathrm{Fe}^{3+}$ ions with low detection limits and good reusability up to five cycles.
\end{abstract}

Keywords: coordination polymer; crystal structure analysis; entanglement; luminescence

\section{Introduction}

Coordination polymers (CPs) have shown potential applications in luminescent sensing, gas storage and separation, drug delivery, catalysis, ion exchange and magnetism [1-5]. Metal ions are linked together by organic ligands to form extended frameworks, which are often porous and comprised into infinite arrays. In addition, polycarboxylates play a vital role in the organization of diverse CPs with differential dimensionalities, which show multiple potential coordination sites that are highly active to coordinate with metal centers. Linear and angular types of polycarboxylate ligands have been used extensively in the preparation of CPs in a mixed system [6,7]. Entanglement involving interpenetration, polycatenation and self-catenation is a very interesting phenomenon, which is also a major factor contributing to the diversities of CPs due to their aesthetic and intriguing topological interests [8]. Despite many such interesting CPs being reported, the manipulation of the structural diversity is still a challenge.

Considerable effort has been invested into understanding the entanglement of CPs containing bis-pyridyl-bis-amide (bpba) ligands [9-13]. Two highly interpenetrated Zn(II) and $\mathrm{Cd}(\mathrm{II}) \mathrm{CPs}$ with eight- and nine-fold interpenetrating diamondoid modes, respectively, have been reported by using the long flexible $N, N^{\prime}$-di(4-pyridyl)adipoamide ligand and the short rigid 1,4-benzenedicarboxylic acid [13]. Construction of a high-fold interpenetrating diamondoid framework with linear bidentate ligand may thus be ascribed to the length and flexibility of the spacer ligands and the geometrical arrangements of the metal centers that may modulate pore size and shape in a single network. While the entanglement may reduce the solvent accessible volume required for the molecules/metal ions adsorptions, the modulated pore size and shape may enhance the selectivity. Moreover, the tunable porosity of luminescent CPs has a great impact on the sensitivity and selectivity for the detection of volatile organic compounds (VOCs) and metal ions that are harmful to the environment and public health [14]. 
In this study, three $\mathrm{CPs}$ constructed from the angular ligand 4,4-oxybis( $\mathrm{N}$-(pyridine-4yl)-benzamide (L), 1,4- $\mathrm{H}_{2} \mathrm{NDC}$ and divalent metal salts, namely, $\left[\mathrm{Zn}(\mathbf{L})(1,4-\mathrm{NDC}) \cdot \mathrm{H}_{2} \mathrm{O}\right]_{\mathbf{n}}, \mathbf{1}$, $\left[\mathrm{Cd}(\mathbf{L})(1,4-\mathrm{NDC})\left(\mathrm{H}_{2} \mathrm{O}\right) \cdot \mathrm{MeOH}\right]_{\mathrm{n}}, \mathbf{2}$, and $\left[\mathrm{Co}(\mathbf{L})(1,4-\mathrm{NDC})\left(\mathrm{H}_{2} \mathrm{O}\right)_{0.5} \cdot \mathrm{MeOH}\right]_{n}, \mathbf{3}$, are reported, which show eight-fold interpenetrating diamondoid networks. Complexes $\mathbf{1}$ and $\mathbf{2}$ exhibit different emission intensity enhancement for distinct VOCs, and show a high sensitivity toward detection of $\mathrm{Fe}^{3+}$ ion in aqueous systems. The synthesis, structural characterization and the detections of VOCs and metal ions of these CPs form the subject of this report.

\section{Materials and Methods}

\subsection{General Procedures}

Elemental analyses of $(\mathrm{C}, \mathrm{H}, \mathrm{N})$ were performed on a PE 2400 series II CHNS/O (PerkinElmer Instruments, Shelton, CT, USA) or an Elementar Vario EL III analyzer (Elementar Analysensysteme $\mathrm{GmbH}$, Hanau, German). Infrared spectra were obtained from a JASCO FT/IR-460 Plus spectrometer with pressed KBr pellets (JASCO, Easton, MD, USA). Thermal gravimetric analyses (TGA) were carried out on an SII Nano Technology Inc. TG/DTA 6200 over the temperature range of 30 to $900{ }^{\circ} \mathrm{C}$ at a heating rate of $10^{\circ} \mathrm{C} \mathrm{min}-1$ under $\mathrm{N}_{2}$ (SEIKO Instruments Inc., Chiba, Japan). UV-vis spectrum was performed on a UV-2450 spectrophotometer (Dongguan Hongcheng Optical Products Co., Dongguan, China). Emission spectra for the solid samples were determined with a Hitachi F-4500 fluorescence spectrophotometer (Hitachi, Tokyo, Japan). Gas sorption measurements were conducted using a Micromeritics ASAP 2020 system (Micromeritics Instruments Co., Norcross, GA, USA). Powder X-ray diffraction patterns were carried out with a Bruker D8-Focus Bragg-Brentano X-ray powder diffractometer equipped with a $\mathrm{CuK} \alpha$ sealed tube $\left(\lambda_{\alpha}=1.54178 \AA\right)$ at $40 \mathrm{kV}$ and $40 \mathrm{~mA}$ (Bruker Corporation, Karlsruhe, Germany).

\subsection{Materials}

The reagent $\mathrm{Zn}(\mathrm{OAc})_{2} \cdot 2 \mathrm{H}_{2} \mathrm{O}$ was purchased from SHOWA Co. (Saitama, Japan), $\mathrm{Cd}(\mathrm{OAc})_{2} \cdot 2 \mathrm{H}_{2} \mathrm{O}$ from Fisher Scientific Co. (Hampton, NY, USA), $\mathrm{Co}(\mathrm{OAc})_{2} \cdot 4 \mathrm{H}_{2} \mathrm{O}$ from J. T. Baker Co. (Phillipsburg, NJ, USA), and naphthalene-1,4-dicarboxylic acid (1,4- $\left.\mathrm{H}_{2} \mathrm{NDC}\right)$ from Alfa Aesar Co. (Ward Hill, MA, USA). The ligand 4,4'-oxybis(N-(pyridine-4-yl)benzamide) (L) was prepared according to a published procedure with some modification [15].

\subsection{Preparations}

\subsection{1. $\left[\mathrm{Zn}(\mathrm{L})(1,4-\mathrm{NDC}) \cdot \mathrm{H}_{2} \mathrm{O}\right]_{\mathrm{n}}, \mathbf{1}$}

$\mathrm{Zn}(\mathrm{OAc})_{2} \cdot 2 \mathrm{H}_{2} \mathrm{O}(0.022 \mathrm{~g}, 0.10 \mathrm{mmol}), \mathbf{L}(0.041 \mathrm{~g}, 0.10 \mathrm{mmol})$ and $1,4-\mathrm{H}_{2} \mathrm{NDC}(0.022 \mathrm{~g}$, $0.10 \mathrm{mmol}$ ) in $8 \mathrm{~mL} \mathrm{H}_{2} \mathrm{O}$ and $2 \mathrm{~mL}$ methanol were sealed in a $23 \mathrm{~mL}$ Teflon-lined flask inside a stainless steel autoclave, which was heated at $120^{\circ} \mathrm{C}$ for 2 days, and then the reaction system was cooled down at a rate of $2{ }^{\circ} \mathrm{C}$ per hour until the room temperature was reached. Colorless crystals were obtained, which were purified with methanol. Yield: $0.041 \mathrm{~g}(58 \%)$, using $\mathrm{Zn}(\mathrm{II})$ as the limited reagent. Anal. calcd. for $\mathrm{C}_{36} \mathrm{H}_{26} \mathrm{~N}_{4} \mathrm{O}_{8} \mathrm{Zn}$ (MW = 707.98): C, 61.07; N, 7.91; H, 3.70\%. Found: C, 61.22; N, 8.07; H, 4.01\%. FT-IR $\left(\mathrm{cm}^{-1}\right)$ : 3237(m, N-H), 3168(m, N-H), 3070(w), 1686(s), 1596(s), 1512(s), 1490(s), 1429(m), 1332(m), 1236(m), 1210(m), 1170(s).

\subsection{2. $\left[\mathrm{Cd}(\mathbf{L})(1,4-\mathrm{NDC})\left(\mathrm{H}_{2} \mathrm{O}\right) \cdot \mathrm{MeOH}\right]_{\mathrm{n}}, 2$}

The procedures for $\mathbf{2}$ were similar to $\mathbf{1}$ except $\mathrm{Cd}(\mathrm{OAc})_{2} \cdot 2 \mathrm{H}_{2} \mathrm{O}(0.013 \mathrm{~g}, 0.05 \mathrm{mmol}), \mathbf{L}$ $(0.021 \mathrm{~g}, 0.05 \mathrm{mmol})$ and 1,4- $\mathrm{H}_{2} \mathrm{NDC}(0.011 \mathrm{~g}, 0.05 \mathrm{mmol})$ in $2 \mathrm{~mL} \mathrm{H}_{2} \mathrm{O}$ and $8 \mathrm{~mL}$ methanol were used. Colorless crystals were obtained. Yield: $0.023 \mathrm{~g} \mathrm{(58 \% ).} \mathrm{Anal.} \mathrm{calcd.} \mathrm{for}$ $\mathrm{C}_{37} \mathrm{H}_{30} \mathrm{CdN}_{4} \mathrm{O}_{9}(\mathrm{MW}=787.05): \mathrm{C}, 56.34 ; \mathrm{N}, 7.11 ; \mathrm{H}, 3.80 \%$. Found: $\mathrm{C}, 55.69 ; \mathrm{N}, 7.05 ; \mathrm{H}$, $3.44 \%$. FT-IR (cm $\left.{ }^{-1}\right): 3168(\mathrm{~m}), 3068(\mathrm{~m}), 1664(\mathrm{~s}), 1595(\mathrm{~s}), 1552(\mathrm{~s}), 1494(\mathrm{~s}), 1426(\mathrm{~s}), 1364(\mathrm{~s})$, 1334(s), 1289(m), 1235(s), 1211(m), 1169(s), 1100(m), 1016(m), 836(m), 760(m), 583(m). 


\subsection{3. $\left[\mathrm{Co}(\mathbf{L})(1,4-\mathrm{NDC})\left(\mathrm{H}_{2} \mathrm{O}\right)_{0.5} \cdot \mathrm{MeOH}\right]_{\mathrm{n}}, 3$}

Complex 3 was prepared according to the procedures for 1 except $\mathrm{Co}(\mathrm{OAc})_{2} \cdot 4 \mathrm{H}_{2} \mathrm{O}$ $(0.025 \mathrm{~g}, 0.10 \mathrm{mmol}), \mathbf{L}(0.041 \mathrm{~g}, 0.10 \mathrm{mmol})$ and $1,4-\mathrm{H}_{2} \mathrm{NDC}(0.022 \mathrm{~g}, 0.10 \mathrm{mmol})$ were used. Purple crystals were obtained. Yield: $0.036 \mathrm{~g}(49 \%)$. Anal. calcd for $\mathrm{C}_{37} \mathrm{H}_{29} \mathrm{CoN}_{4} \mathrm{O}_{8.5}(\mathrm{MW}$ = 724.57): C, 61.33; N, 7.73; H, 4.03\%. Found: C, 60.50; N, 7.56; H, 3.90\%. FT-IR $\left(\mathrm{cm}^{-1}\right)$ : 3230(m), 3158(m), 3069(m), 1683(m), 1595(s), 1510(s), 1494(s), 1427(s), 1363(s), 1330(s), 1274(m), 1235(s), 1208(m), 1170(m), 1098(m), 1022(m), 838(m), 759(w), 584(w). Figure S1 shows the FT-IR spectra of complexes 1-3.

\subsection{X-ray Crystallography}

A Bruker AXS SMART APEX II CCD diffractometer, which was equipped with graphite-monochromated $\operatorname{MoK} \alpha\left(\lambda_{\alpha}=0.71073 \AA\right)$ radiation, was used to collect the diffraction data for complexes 1-3 [16], and the data were reduced by using the well-established computational procedures. The structure factors were treated with Lorentz and polarization corrections and an empirical absorption correction based on "multi-scan" [17]. The Direct or Patterson method was applied to locate the positions of some of the heavier atoms, and the remaining atoms were identified in several alternating difference Fourier maps and least-square refinements. Hydrogen atoms were added by using the HADD command in SHELXTL. The coordinated water molecule, $\mathrm{O}(8)$, of complex $\mathbf{2}$ is disordered such that two orientations of the oxygen atom can be found, and the occupancy of each orientation was set to be 0.5 and were refined isotropically. Moreover, the occupancy of $\mathrm{O}(8)$ of 3 was refined to be 0.5 . Table 1 lists the basic information regarding the crystal parameters and structure refinement.

Table 1. Crystal data for complexes 1-3.

\begin{tabular}{|c|c|c|c|}
\hline Complex & 1 & 2 & 3 \\
\hline Formula & $\mathrm{C}_{36} \mathrm{H}_{26} \mathrm{ZnN}_{4} \mathrm{O}_{8}$ & $\mathrm{C}_{37} \mathrm{H}_{30} \mathrm{CdN}_{4} \mathrm{O}_{9}$ & $\mathrm{C}_{37} \mathrm{H}_{29} \mathrm{CoN}_{4} \mathrm{O}_{8.5}$ \\
\hline Formula weight & 707.98 & 787.05 & 724.57 \\
\hline Crystal system & monoclinic & monoclinic & monoclinic \\
\hline Space group & $P 2_{1} / c$ & $P 2_{1} / n$ & $P 2_{1} / n$ \\
\hline$a, \AA$ & $9.78070(1)$ & $8.5591(4)$ & $8.5240(6)$ \\
\hline $\mathrm{b}, \AA$ & $19.3224(2)$ & 21.5741(11) & $21.5176(16)$ \\
\hline$c, \AA$ & $17.9006(2)$ & $19.0086(9)$ & $18.1376(13)$ \\
\hline$\alpha,{ }^{\circ}$ & 90 & 90 & 90 \\
\hline$\beta, \circ$ & 103.1124(8) & $98.065(3)$ & $96.850(2)$ \\
\hline$\gamma,{ }^{\circ}$ & 90 & 90 & 90 \\
\hline $\mathrm{V}, \AA^{3}$ & $3294.77(6)$ & $3475.3(3)$ & $3303.0(4)$ \\
\hline $\mathrm{Z}$ & 4 & 4 & 4 \\
\hline $\mathrm{D}_{\text {calc }}, \mathrm{mg} / \mathrm{m}^{3}$ & 1.427 & 1.504 & 1.457 \\
\hline $\mathrm{F}(000)$ & 1456 & 1600 & 1496 \\
\hline$\mu\left(\mathrm{MoK}_{\alpha}\right), \mathrm{mm}^{-1}$ & 0.805 & 0.690 & 0.582 \\
\hline $\begin{array}{c}\text { Range }(2 \theta) \text { for data collection, } \\
\text { deg. }\end{array}$ & $3.14 \leq 2 \theta \leq 52.00$ & $2.87 \leq 2 \theta \leq 52.00$ & $4.41 \leq 2 \theta \leq 50.12$ \\
\hline Independent reflections & $6474[\mathrm{R}(\mathrm{int})=0.0398]$ & $6845[\mathrm{R}(\mathrm{int})=0.0633]$ & $5855[\mathrm{R}(\mathrm{int})=0.1880]$ \\
\hline Data/restraints/parameters & $6474 / 0 / 437$ & $6845 / 1 / 496$ & $5855 / 0 / 487$ \\
\hline Quality-of-fit indicator ${ }^{a}$ & 1.034 & 1.076 & 1.027 \\
\hline Final $R$ indices $[I>2 \sigma(I)]^{b, c}$ & $\begin{array}{r}\mathrm{R} 1=0.0618 \\
\mathrm{wR} 2=0.1761\end{array}$ & $\begin{array}{r}\mathrm{R} 1=0.0648 \\
\mathrm{wR} 2=0.1609\end{array}$ & $\begin{array}{r}\mathrm{R} 1=0.0655 \\
\mathrm{wR} 2=0.1477\end{array}$ \\
\hline $\mathrm{R}$ indices (all data) & $\begin{array}{c}\mathrm{R} 1=0.0871 \\
\mathrm{wR} 2=0.1939\end{array}$ & $\begin{array}{c}\mathrm{R} 1=0.0935 \\
\mathrm{wR} 2=0.1751\end{array}$ & $\begin{array}{c}\mathrm{R} 1=0.1986 \\
\mathrm{wR} 2=0.2248\end{array}$ \\
\hline
\end{tabular}

${ }^{\mathrm{a}}$ quality-of-fit $\left.=\left[\Sigma \mathrm{w}\left(\left|\mathrm{F}_{\mathrm{o}}{ }^{2}\right|-\left|\mathrm{F}_{\mathrm{c}}{ }^{2}\right|\right)^{2} / \mathrm{N}_{\text {observed }}-\mathrm{N}_{\text {parameters }}\right)\right]^{1 / 2} \cdot{ }^{\mathrm{b}} \mathrm{R}_{1}=\Sigma|| \mathrm{F}_{\mathrm{o}}|-| \mathrm{F}_{\mathrm{c}}|| / \Sigma\left|\mathrm{F}_{\mathrm{o}}\right| \mathrm{c}^{\mathrm{c}} \mathrm{wR}_{2}=\left[\Sigma \mathrm{w}\left(\mathrm{F}_{\mathrm{o}}{ }^{2}-\mathrm{F}_{\mathrm{c}}{ }^{2}\right)^{2} / \Sigma\left(\mathrm{F}_{\mathrm{o}}{ }^{2}\right)^{2}\right]^{1 / 2}$. $\mathrm{w}=1 /\left[\sigma^{2}\left(\mathrm{~F}_{\mathrm{o}}^{2}\right)+(\mathrm{ap})^{2}+(\mathrm{bp})\right], \mathrm{p}=\left[\max \left(\mathrm{F}_{\mathrm{o}}^{2}\right.\right.$ or 0$\left.)+2\left(\mathrm{~F}_{\mathrm{c}}{ }^{2}\right)\right] / 3.1, \mathrm{a}=0.1067, \mathrm{~b}=3.1664 ; 2, \mathrm{a}=0.0754, \mathrm{~b}=7.0332 ; 3, \mathrm{a}=0.0849, \mathrm{~b}=3.8585$ 


\section{Results and Discussion}

\subsection{Crystal Structures of 1-3}

Complexes 1-3 are isostructural and their single crystals conform to the monoclinic system. While the crystal structure of $\mathbf{1}$ was solved in the space group $P 2_{1} / c$, those of $\mathbf{2}$ and 3 were in $P 2_{1} / n$. Their asymmetric units are mainly composed of one divalent metal ion [Zn(II), $\mathbf{1} ; \mathrm{Cd}(\mathrm{II}), 2$ and $\mathrm{Co}(\mathrm{II}), 3]$, one $\mathbf{L}$ and one $1,4-\mathrm{NDC}^{2-}$ ligands, and there is also one cocrystallized water molecule in 1, one coordinated water and one cocrystallized $\mathrm{MeOH}$ molecule in 2, and a half coordinated water and one cocrystallized $\mathrm{MeOH}$ molecule in 3 , respectively. Figure 1a-c depict the drawings showing the coordination environments about the metal ions of complexes $\mathbf{1}-\mathbf{3}$. The $\mathrm{Zn}$ (II) ions of $\mathbf{1}$ is four-coordinated by two pyridyl nitrogen atoms $[\mathrm{Zn}-\mathrm{N}=2.024(3) \AA$ and 2.037(3) $\AA]$ from two L ligands and two carboxylate oxygen atoms $[\mathrm{Zn}-\mathrm{O}=1.905(5)$ and $1.940(3) \AA]$ from two $1,4-\mathrm{NDC}^{2-}$ ligands, forming a distorted tetrahedral geometry, while the $\mathrm{Cd}(\mathrm{II})$ ion of $\mathbf{2}$ is seven-coordinated by two pyridyl nitrogen atoms [Cd-N $=2.272(5)$ and 2.297(5) $\AA$ ] from two L ligands, four carboxylate oxygen atoms $[\mathrm{Cd}-\mathrm{O}=2.248(5)-2.577(4) \AA]$ from two 1,4-NDC ${ }^{2-}$ ligands and one oxygen atom $[\mathrm{Cd}-\mathrm{O}=2.416(13) \AA]$ of the coordinated water molecule, resulting in a distorted pentagonal bipyramidal geometry. As shown in the X-ray crystallographic section, the occupancy of the coordinated water of 3 was refined to be 0.5 ; six and five coordination are thus possible for the $\mathrm{Co}$ (II) ion. The six-coordinated $\mathrm{Co}(\mathrm{II})$ ion is supported by two pyridyl nitrogen atoms [Co- $\mathrm{N}=2.069(5)$ and 2.088(6) $\AA]$ from two L ligands, three carboxylate oxygen atoms $[\mathrm{Co}-\mathrm{O}=1.913(10)-2.302(5) \AA]$ from two $1,4-\mathrm{NDC}^{2-}$ ligands and one oxygen atom $[\mathrm{Co}-\mathrm{O}=2.238(9) \AA]$ of the coordinated water molecule, revealing a distorted octahedral geometry, while the removal of the $\mathrm{O}(8)$ atom results in a fivecoordinated $\mathrm{Co}(\mathrm{II})$ ion and forms a distorted square pyramidal geometry.

Considering the divalent metal ions as four-connection nodes and the ligands as linkers, the structures of $1-3$ can be simplified as 3D nets with the $\left(6^{6}\right)$-dia topology (Figure 1d) revealing the 8-fold [4+4] interpenetration (Figure 1e), determined using ToposPro [18]. Noticeably, the diamondoid Zn(II) and Cd(II) CPs constructed from the flexible $N, N^{\prime}$-di(4-pyridyl)adipoamide and 1,4-benzenedicarboxylic acid show eight- and nine-fold interpenetrating modes, respectively [13], indicating the nature of the metal center alters the degree of interpenetration. In marked contrast, complexes $\mathbf{1}$ and $\mathbf{2}$ with the $\mathrm{Zn}$ (II) and Cd(II) ions, respectively, are both eight-fold interpenetrated, demonstrating that the degree of interpenetration of the diamondoid CPs in mixed systems is also subject to the changes of the shape and flexibility of the polycarboxylate and bpba ligands.

\subsection{Ligand Conformations and Bonding Modes}

For the bpba ligand, the two $\mathrm{C}=\mathrm{O}$ (or N-H) groups that are on the same and opposite directions define the cis and trans conformations, respectively [19]. Accordingly, all of the L ligands in 1-3 adopt the cis conformation. A schematic drawing defining the C-O-C $(\theta)$ angle and dihedral angle (d) is shown in Figure 2, and the angles were calculated and listed in Table 2. Clearly, although all of the $\mathbf{L}$ ligands in 1-3 adopt the same cis conformation, they differ in the dihedral angles, presumably due to the different metal identity. 


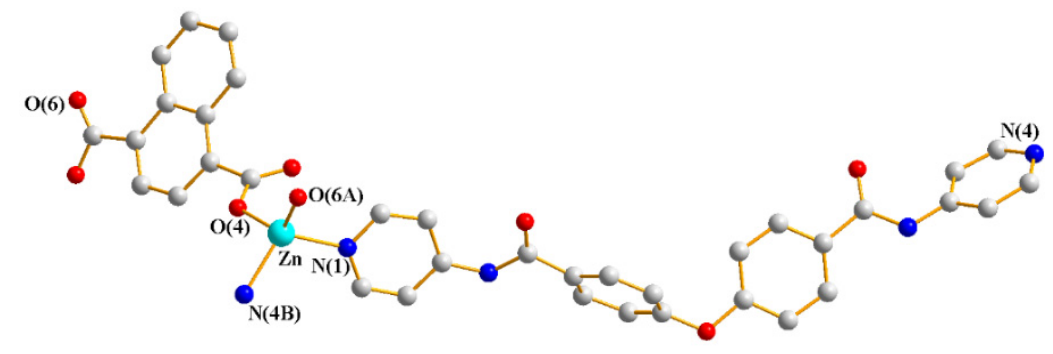

(a)

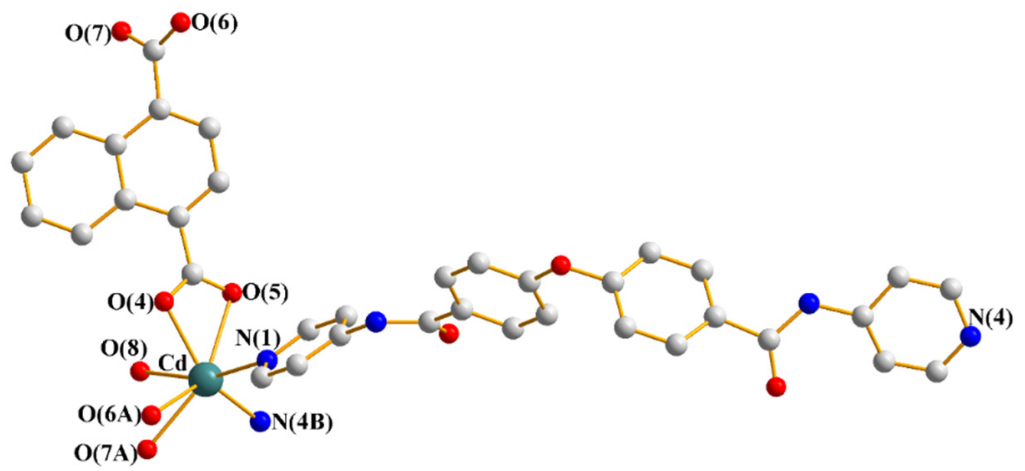

(b)

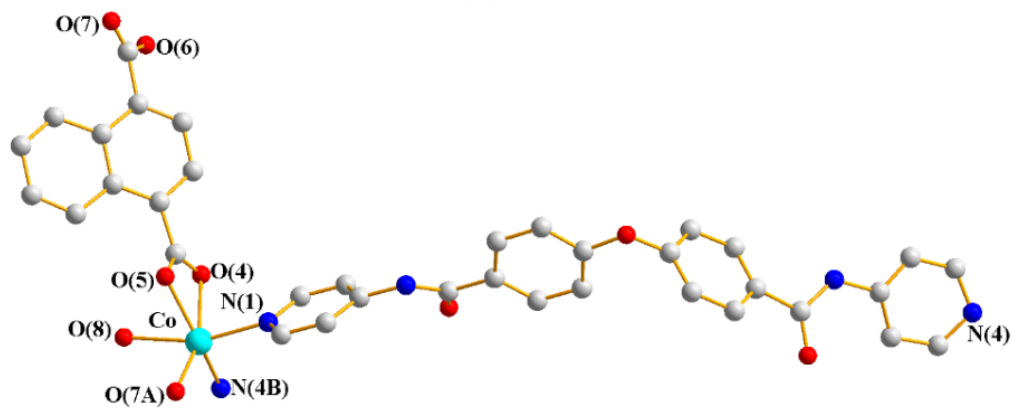

(c)

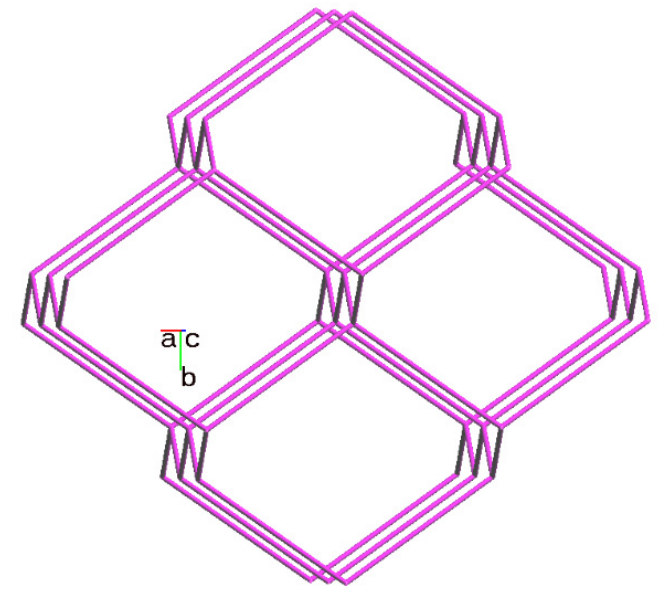

(d)

Figure 1. Cont. 


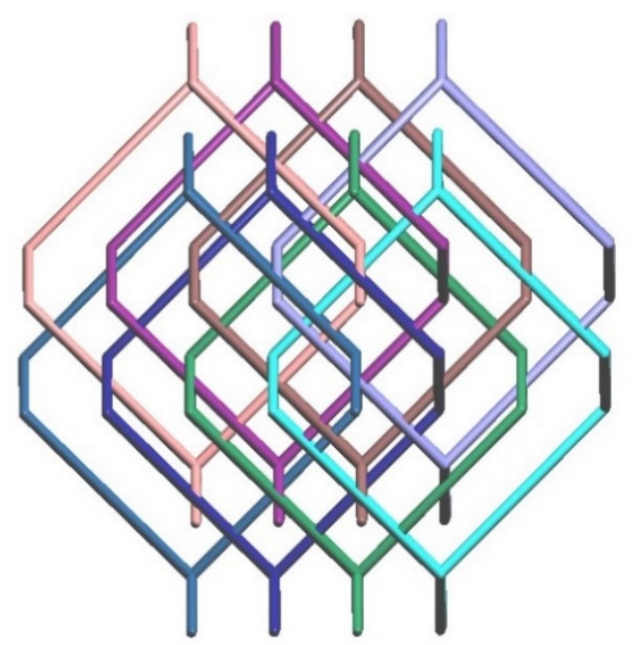

(e)

Figure 1. Coordination environments about the (a) $\mathrm{Zn}$ (II) ion in 1. Symmetry transformations used to generate equivalent atoms: (A) $x,-y+5 / 2, z-1 / 2$; (B) $x-2,-y+3 / 2, z-1 / 2$; (b) Cd(II) ion in 2 . Symmetry transformations used to generate equivalent atoms: (A) $x+1 / 2,-y+3 / 2, z+1 / 2$; (B) $x-$ $3 / 2,-y+1 / 2, z+1 / 2$; and (c) $\mathrm{Co}$ (II) ion in 3 . Symmetry transformations used to generate equivalent atoms: (A) $\mathrm{x}-3 / 2,-\mathrm{y}+1 / 2, \mathrm{z}+1 / 2 ;$ (B) $\mathrm{x}+1 / 2,-\mathrm{y}+3 / 2, \mathrm{z}+1 / 2$. (d) A drawing showing a 3D framework with the dia topology. (e) A schematic view of the eight-fold $[4+4]$ interpenetration.

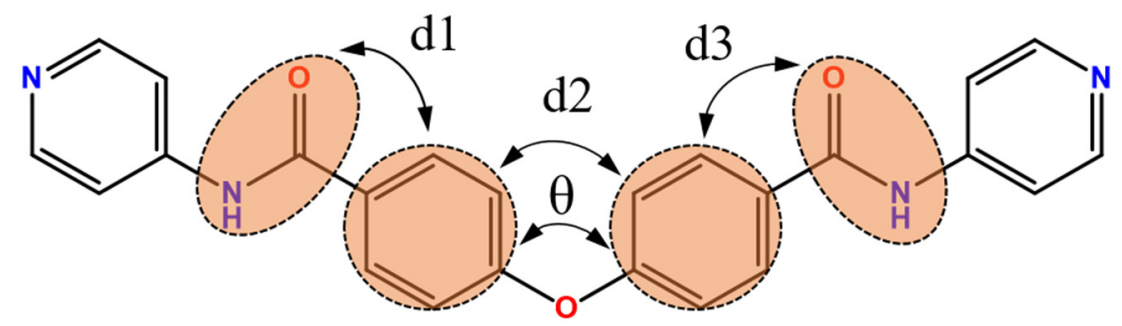

Figure 2. A drawing defining the C-O-C $(\theta)$ and dihedral angles (d) for $\mathbf{L}$.

Table 2. Selected angles of the L ligands in complexes 1-3.

\begin{tabular}{ccccc}
\hline \multirow{2}{*}{ Complex } & \multirow{2}{*}{ C-O-C Angle $\left({ }^{\circ}\right)$} & \multicolumn{3}{c}{ Dihedral Angle ${ }^{\circ}$ ) } \\
\cline { 3 - 5 } & & d1 & d2 & d3 \\
\hline $\mathbf{1}$ & 117.0 & 30.49 & 74.52 & 21.12 \\
$\mathbf{2}$ & 116.9 & 25.51 & 87.63 & 35.97 \\
$\mathbf{3}$ & 116.9 & 28.54 & 88.70 & 34.02 \\
\hline
\end{tabular}

Moreover, the 1,4-NDC ${ }^{2-}$ ligand of 1 bridge two $\mathrm{Zn}(\mathrm{II})$ ions through two carboxylate oxygen atoms from two carboxylate groups to reveal the coordination mode I, while those of 2 and $\mathbf{3}$ chelate and bridge two metal ions through four carboxylate oxygen atoms, coordination mode II, and three carboxylate oxygen atoms, coordination mode III, respectively (Figure 3). Noticeably, while the $\mathrm{Zn}(\mathrm{II}), \mathrm{Cd}(\mathrm{II})$ and $\mathrm{Co}(\mathrm{II})$ metal centers of 1-3 adopt the distorted tetrahedral, pentagonal bipyramidal and octahedral (square pyramidal) geometries, respectively, giving rise to different coordination modes for the $1,4-\mathrm{NDC}^{2-}$ ligands; their structural topologies are not subject to the metal identities. 


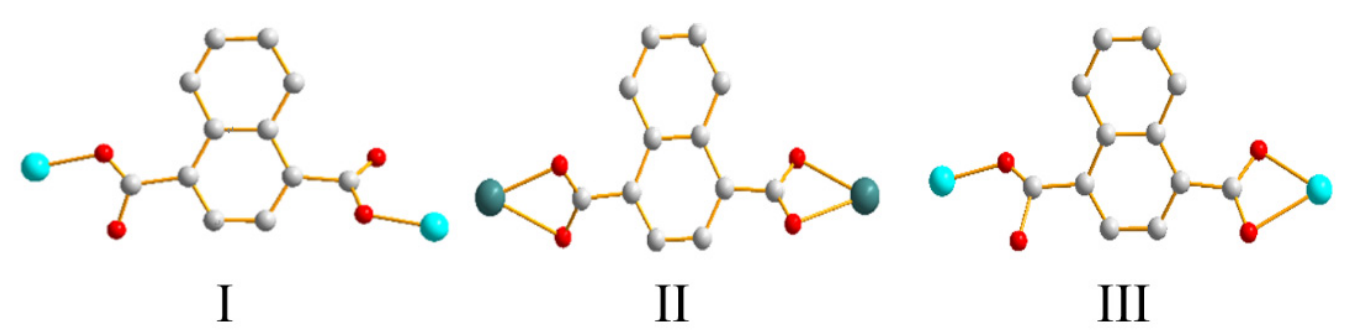

Figure 3. Various coordination modes of 1,4-NDC ${ }^{2-}$ ligands in 1-3.

\subsection{PXRD Patterns and Thermal Analysis}

As shown in Figures S2-S4, the experimental PXRD patterns of complexes 1-3 are in consistency with their corresponding simulated ones, demonstrating the purities of the bulk samples. On the other hand, their thermal gravimetric analysis (TGA) curves performed in a nitrogen atmosphere from 30 to $800{ }^{\circ} \mathrm{C}$ (Figure S5) display two-step weight losses involving removal of cocrystallized solvents and the coordinated ligands were found. From Table 3, it can be shown that the starting temperature for the removal of the organic ligands of $3,300{ }^{\circ} \mathrm{C}$, is higher than those of $\mathbf{1 - 2}$, probably indicating that the framework of 3 is stronger than those of $\mathbf{1 - 2}$ upon heating.

Table 3. Thermal properties of $\mathbf{1}-\mathbf{3}$.

\begin{tabular}{ccc}
\hline Complex. & $\begin{array}{c}\text { Weight Loss of Solvents } \\
{ }^{\circ} \mathbf{C} \text { (found/calc), \% }\end{array}$ & $\begin{array}{c}\text { Weight Loss of Ligands } \\
{ }^{\circ} \mathbf{C} \text { (found/calc), \% }\end{array}$ \\
\hline $\mathbf{1}$ & $\sim 120(2.76 / 2.54)$ & $240-800(84.89 / 88.21)$ \\
$\mathbf{2}$ & $\sim 140(3.33 / 4.07)$ & $250-800(80.83 / 81.90)$ \\
$\mathbf{3}$ & $\sim 145(3.25 / 4.42)$ & $300-800(87.34 / 87.64)$ \\
\hline
\end{tabular}

\subsection{Chemical Stability}

To estimate the chemical stability, the PXRD patterns of complexes 1-3 in water, as well as their dehydration and rehydration products, were measured. Complexes 1-3 were first immersed into water for seven days and then dried under vacuum. Figures S6-S8 show that only complexes $\mathbf{1}$ and $\mathbf{2}$ are stable in water. Moreover, dehydration (heated at $150^{\circ} \mathrm{C}$ for $1 \mathrm{~h}$ ) and rehydration (immersed into water for $1 \mathrm{~h}$ ) of complexes 1 and 2 gave PXRD patterns comparable to the simulated ones, indicating the stability upon solvent removal and adsorption. The stabilities of $\mathbf{1}$ and $\mathbf{2}$ in acidic and basic solutions at $50{ }^{\circ} \mathrm{C}$ for $24 \mathrm{~h}$ were further investigated. As shown in Figures S9 and S10, the PXRD patterns of $\mathbf{1}$ in $\mathrm{pH} 2-12$ and 2 in $\mathrm{pH} 4-10$ are almost identical to the simulated ones, suggesting the better acid and base resistances of $\mathbf{1}$ than $\mathbf{2}$.

\subsection{Gas Sorption}

The low-pressure gas sorption properties at $273 \mathrm{~K}$ and $298 \mathrm{~K}$ were examined for complexes 1 and 2 and confirmed by $\mathrm{CO}_{2}$ gas absorption and desorption isotherms, resulting in a type II isotherm behavior [20,21]. As illustrated in Figures S11-S13, the experimental amount of adsorbed $\mathrm{CO}_{2}$ gas in the sample at $273 \mathrm{~K}$ is higher than that at $298 \mathrm{~K}$. While desolvated samples of 1 and 2 adsorbed 1.40565 and $1.55795 \mathrm{mmol} / \mathrm{g}$ of $\mathrm{CO}_{2}$ at $273 \mathrm{~K}$, they adsorbed 0.83070 and $1.05312 \mathrm{mmol} / \mathrm{g}$ at $298 \mathrm{~K}$, respectively. The Brunauer-EmmettTeller (BET) surface areas of $\mathbf{1}$ and $\mathbf{2}$ evaluated from the $\mathrm{CO}_{2}$ gas uptake are 411.3 and $302.4 \mathrm{~m}^{2} \mathrm{~g}^{-1}$ and the Langmuir surface areas are 482.6 and $330.5 \mathrm{~m}^{2} \mathrm{~g}^{-1}$ at $273 \mathrm{~K}$, with total pore volumes of 0.05 and $0.06 \mathrm{~cm}^{3} \mathrm{~g}^{-1}$, respectively. The pore size distribution and sorption/desorption hysteresis are presumably related to very narrow pore sizes. Calculations using nonlocal density functional theory based on $\mathrm{CO}_{2}$ sorption data at $273 \mathrm{~K}$ suggest that the pore sizes for $\mathbf{1}$ and $\mathbf{2}$ are similar and are around $1.06 \mathrm{~nm}$, respectively, indicating microporous materials. The PXRD patterns of the samples of $\mathbf{1}$ and $\mathbf{2}$ measured after the 
experiments match quite well with those of the simulated ones, indicating permanent porous features of $\mathbf{1}$ and $\mathbf{2}$ (Figure S13c,d).

\subsection{Photoluminescence Properties}

An ample number of studies have shown that $\mathrm{CPs}$ with $\mathrm{d}^{10}$ metal centers exhibit great sensing properties [22-26]. Therefore, the solid-state emission spectra of the water-stable 1 and 2 , as well as $1,4-\mathrm{H}_{2} \mathrm{NDC}$ and $\mathbf{L}$ ligands, were investigated at room temperature and the results are shown in Figure S14 and Table 4. The emission band of $\mathbf{L}$ appears at $468 \mathrm{~nm}$ upon excitation at $376 \mathrm{~nm}$, while 1,4- $\mathrm{H}_{2} \mathrm{NDC}$ exhibits an intense emission band at $480 \mathrm{~nm}$ upon two excitations at 280 and $370 \mathrm{~nm}$, which may be attributed to intra-ligand $\pi^{*} \rightarrow \pi$ or $\pi^{*} \rightarrow n$ transition.

Table 4. Luminescent properties of $\mathbf{L}, 1,4-\mathrm{H}_{2} \mathrm{NDC}, \mathbf{1}$ and $\mathbf{1 a}, 2$ and $\mathbf{2 a}$.

\begin{tabular}{cccccc}
\hline Compound & $\begin{array}{c}\text { Excitation } \\
\boldsymbol{\lambda}_{\mathbf{e x}}(\mathbf{n m})\end{array}$ & $\begin{array}{c}\text { Emission } \\
\boldsymbol{\lambda}_{\mathbf{e m}}(\mathbf{n m})\end{array}$ & Compound & $\begin{array}{c}\text { Excitation } \\
\boldsymbol{\lambda}_{\mathbf{e x}}(\mathbf{n m})\end{array}$ & $\begin{array}{c}\text { Emission } \\
\boldsymbol{\lambda}_{\mathbf{e m}}(\mathbf{n m})\end{array}$ \\
\hline $\mathbf{L}$ & 376 & 468 & $1,4-\mathrm{H}_{2} \mathrm{NDC}$ & 280,370 & 480 \\
$\mathbf{1}$ & 350 & 390 & $\mathbf{1 a}$ & 350 & 390 \\
$\mathbf{2}$ & 350 & 395 & $\mathbf{2 a}$ & 350 & 395 \\
\hline
\end{tabular}

As-synthesized complexes $\mathbf{1}$ and $\mathbf{2}$ may contain water molecules in the pores, they were first activated by immersion into methanol for two days and heated at $80^{\circ} \mathrm{C}$ for $1 \mathrm{~h}$ to give $\mathbf{1 a}$ and $\mathbf{2 a}$, respectively. It can be seen (Figure S15) that complexes $\mathbf{1 a}$ and $\mathbf{2 a}$ show identical emission wavelengths to those of original 1 and 2. Moreover, the PXRD patterns (Figure S16) of $\mathbf{1 a}$ and 2a match quite well with those of $\mathbf{1}$ and 2, respectively, indicating no framework changes and suggesting ligand-based emissions with little contribution from the cocrystallized solvents. The different emission wavelengths in $\mathbf{1}$ and $\mathbf{2}$ are probably due to the distinction in the metal identity and the coordination mode of the 1,4-NDC ${ }^{2-}$ ligand. $\mathrm{Zn}$ (II) and $\mathrm{Cd}(\mathrm{II})$ atoms are more difficult to undergo oxidation and reduction reactions, due to their closed-shell electronic configurations; therefore, the emissions of complexes 1 and $\mathbf{2}$, as well as $\mathbf{1} \mathbf{a}$ and $\mathbf{2 a}$, are probably due to ligand-to-ligand charge transfer (LLCT), while metal-to-ligand charge transfer (MLCT) is also possible.

\subsection{Detection of Volatile Organic Compounds (VOCs)}

The $\mathrm{CO}_{2}$ gas adsorption studies confirm the permanent pores in the eight-fold interpenetrating CPs $\mathbf{1}$ and $\mathbf{2}$, which provide a unique opportunity to investigate the role of the entangled bpba-CPs in the sensing of abundant VOCs [26-32] and metal ions [33]. The activated complexes of $\mathbf{1}$ and $\mathbf{2}, \mathbf{1 a}$ and $\mathbf{2 a}$, were exposed to various VOCs by immersing grounded samples $(30 \mathrm{mg}$ ) into $5 \mathrm{~mL}$ different organic solvents, which were then sonicated for $10 \mathrm{~min}$ and collected by centrifugation and then air dried. The emission spectra of the VOC-absorbed complexes upon excitation at $350 \mathrm{~nm}$ were measured at room temperature (Figure 4a), revealing that the emission intensities of VOC-absorbed 1a and 2a reached the maximum for the mesitylene molecules. The PXRD patterns shown in Figure S16 for the mesitylene absorbed 1a and 2a indicate that they maintain the identical structural frameworks. The luminescence enhancement, $\left[\left(\mathrm{I}-\mathrm{I}_{\mathrm{O}}\right) / \mathrm{I}_{\mathrm{O}}\right]\left(\mathrm{I}_{\mathrm{O}}=\right.$ luminescence intensity of $1 \mathbf{a}$ or $\mathbf{2 a}$; I = luminescence intensity of mesitylene-loaded 1a or $\mathbf{2 a}$ ) due to the adsorption of mesitylene are calculated as 1.91 and 1.65 for $\mathbf{1 a}$ and $\mathbf{2 a}$, respectively. The organic uptakes were estimated from the weight-losses in TGA curves of VOC-loaded 1a and 2a (Figure S17), showing that the uptakes of mesitylene molecules per unit cell are 2.53 in $\mathbf{1 a}$ and 2.97 in 2a, respectively. The emission wavelengths of mesitylene-absorbed $\mathbf{1 a}$ and 2a shows red-shifts of 13 and $11 \mathrm{~nm}$, respectively, compared with solvent-free $\mathbf{1 a}$ and $\mathbf{2 a}$ (Figures S18a and S19a), indicating the possible interligand couplings [34]. The mesitylene molecules may have the strongest $\mathrm{C}-\mathrm{H} \cdots \pi$ interactions with $\mathbf{L}$ linkers among other exposed solvents, inducing the largest bathochromic shift and the intensity enhancement [35]. 
Recently, it has been shown that $\mathrm{C}-\mathrm{H} \cdots \pi$ interaction can be modulated to enhance the luminescence [36].
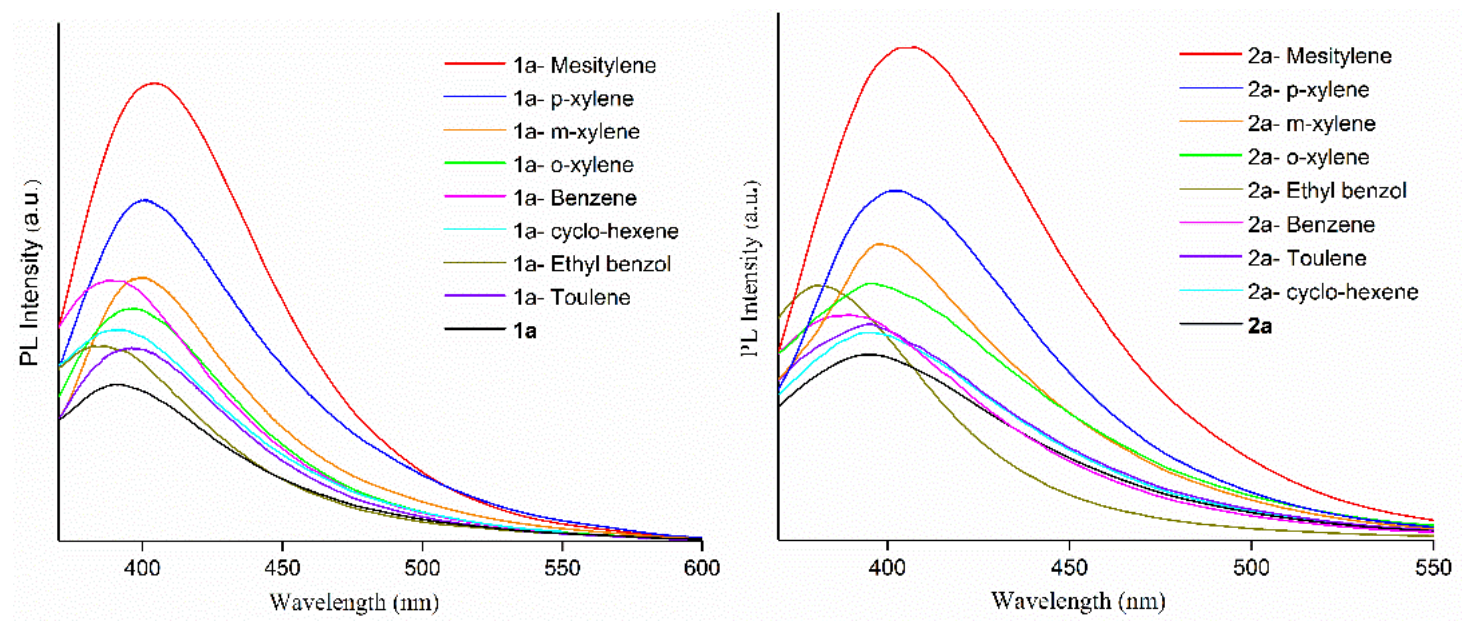

(a)
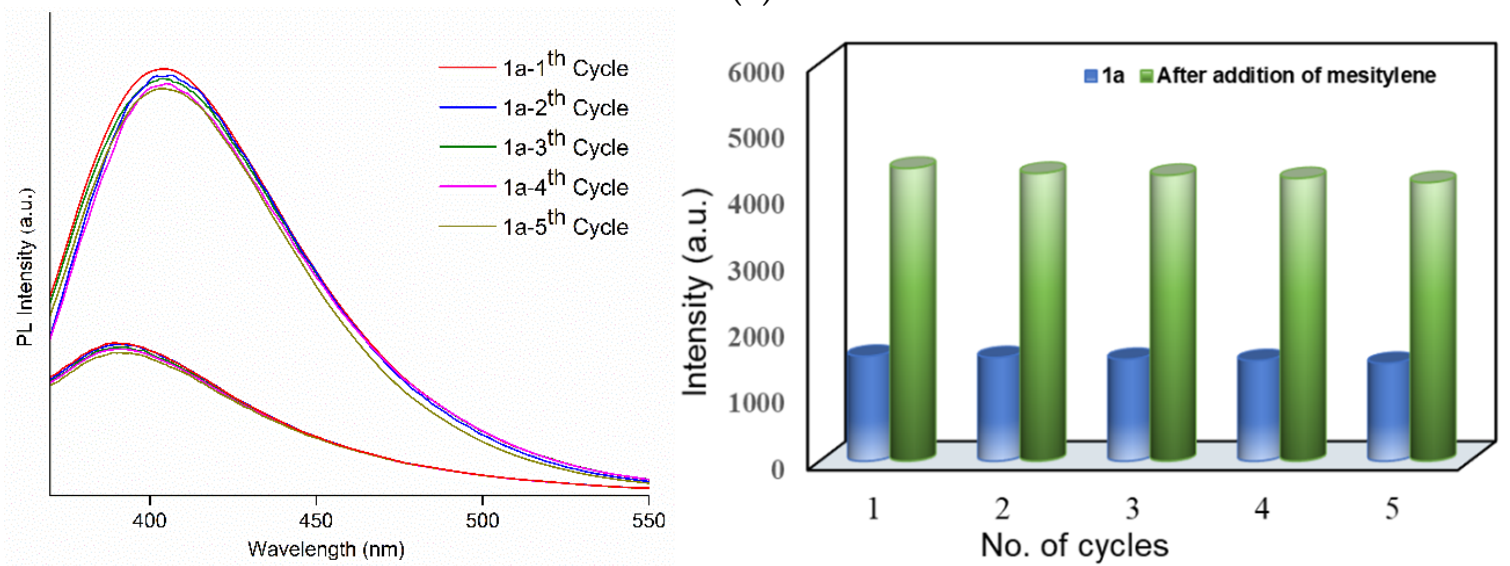

(b)
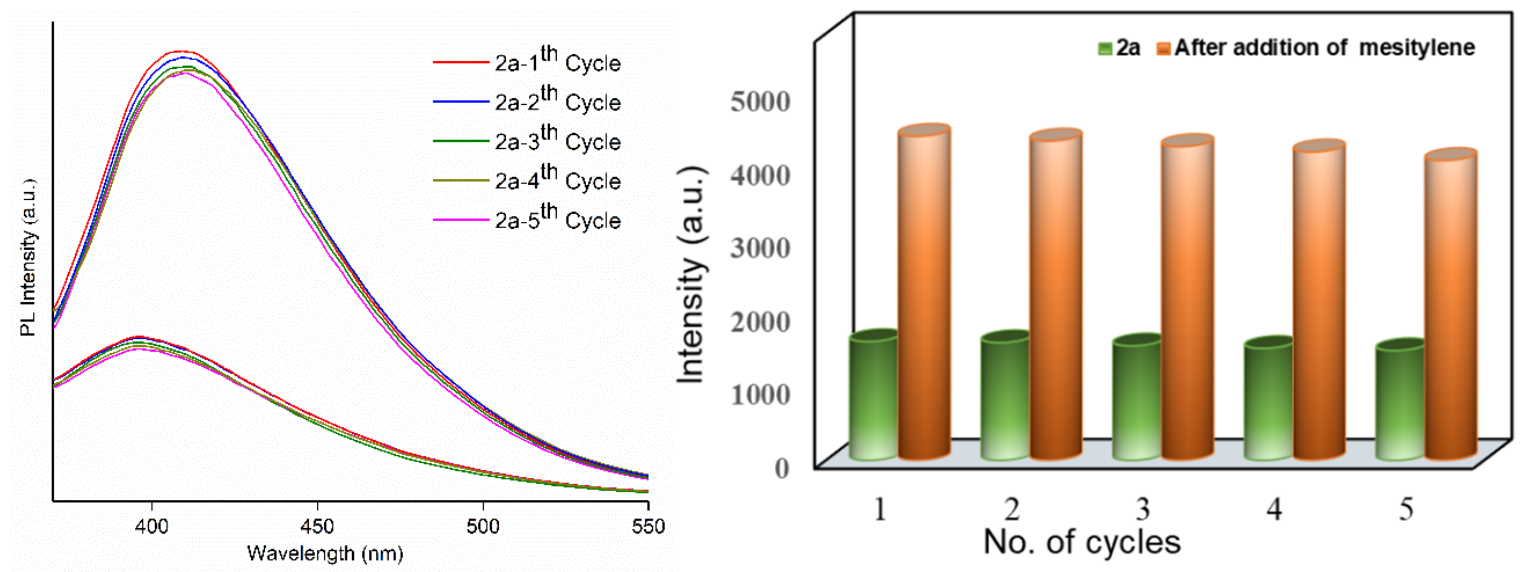

(c)

Figure 4. (a) Emission spectra of activated 1 (left) and 2 (right) loaded with different VOC's. Emission spectra showing the recyclability of $(\mathbf{b}) \mathbf{1 a}$ and (c) 2 a exposed with mesitylene for five repeated cycles. 
To estimate the selective sensing performances of 1a and 2a toward mesitylene, luminescence titration experiments were performed by the addition of the increasing mesitylene $(0-5 \mathrm{~mL})$ to $1 \mathbf{a}$ and $\mathbf{2 a}$. The volume of mesitylene and the emission intensity show linear dependence of $R^{2}=0.983$ and 0.985 (Figures S18b,c and S19b,c). Table S1 shows the intensity enhancements of several reported complexes due to the interactions with the specific organic solvents, showing comparable luminescence enhancements for $\mathbf{1 a}$ and $\mathbf{2 a}$ in the detection of mesitylene molecules. Further, to determine the recyclability of mesitylene adsorption in complexes $\mathbf{1 a}$ and $\mathbf{2 a}$, their luminescence sensing abilities were explored for five regeneration cycles. The PXRD patterns in Figure S16 indicate that the main diffraction peaks of $\mathbf{1 a}$ and $\mathbf{2 a}$ are quite identical with those of the mesitylene-treated samples, while Figure $4 \mathrm{~b}, \mathrm{c}$ display their similar emission spectra and intensities, respectively, suggesting that their frameworks remain rigid for five cycles.

\subsection{Detection of Metal Ions}

In order to explore the potential application of $\mathbf{1}$ and $\mathbf{2}$ in luminescent sensing of metal cations, $30 \mathrm{mg}$ samples of $\mathbf{1}$ and $\mathbf{2}$, respectively, were immersed into $10 \mathrm{~mL}$ aqueous solutions of nitrate salts $\mathrm{M}\left(\mathrm{NO}_{3}\right)_{\mathrm{x}}\left(\mathrm{M}=\mathrm{Al}^{3+}, \mathrm{Cd}^{2+}, \mathrm{Cu}^{2+}, \mathrm{Mg}^{2+}, \mathrm{Ni}^{2+}, \mathrm{Zn}^{2+}, \mathrm{Na}^{+}, \mathrm{K}^{+}\right.$, $\mathrm{Cr}^{3+}$ and $\mathrm{Fe}^{3+}$ ) with a concentration of $1 \times 10^{-3} \mathrm{M}$. After $1 \mathrm{~h}$, the solids were filtered and then the solid-state emission spectra were measured at room temperature. As shown in Figure S20, remarkable luminescence quenching of about $95 \%$ for $\mathbf{1}$ and $92 \%$ for 2 were found in the detection of $\mathrm{Fe}^{3+}$ ions. To further explore the quenching effect of $\mathrm{Fe}^{3+}$ ions, sensing dependence of luminescence intensity on the concentration of $\mathrm{Fe}^{3+}$ was investigated by immersing finely grounded samples $\left(30 \mathrm{mg}\right.$ ) of $\mathbf{1}$ and $\mathbf{2}$ into $\mathrm{Fe}^{3+}$ aqueous solutions with various concentrations $(0.005-0.15 \mathrm{mM})$ for $1 \mathrm{~h}$. As shown in Figure $5 \mathrm{~b}, \mathrm{c}$ (left), the emission intensities were getting lower and almost completely quenched upon increasing the concentration of $\mathrm{Fe}^{3+}$. Quantitatively, the quenching capacity of $\mathrm{Fe}^{3+}$ ion can be rationalized by the Stern-Volmer equation: $\mathrm{I}_{0} / \mathrm{I}=1+\mathrm{K}_{\mathrm{sv}} \times[\mathrm{Q}]$, where [Q] is the concentration of $\mathrm{Fe}^{3+}, \mathrm{K}_{\mathrm{sv}}$ is the quenching constant, and $\mathrm{I}_{0}$ and $\mathrm{I}$ are the emission intensities in the absence and presence of $\mathrm{Fe}^{3+}$, respectively [37]. As demonstrated in Figure $5 b, c$ (right), the titration curves for $\mathrm{Fe}^{3+}$ ions in $\mathbf{1}$ and $\mathbf{2}$ are virtually linear at low concentrations, which gave the linear correlation coefficient $\left(R^{2}\right)$ of 0.997 for $\mathbf{1}$ and 0.975 for 2 , respectively, while the S-V curves at higher concentrations became nonlinear, which can be described by concurrent dynamic and static quenching or the self-absorption process. The Stern-Volmer constant $\left(\mathrm{K}_{\mathrm{sv}}\right)$ values are $6.895 \times 10^{5}$ for $\mathbf{1}$ and $9.940 \times 10^{5} \mathrm{M}^{-1}$ for 2, respectively, in the presence of $\mathrm{Fe}^{3+}$.

Furthermore, the detection limits were calculated according to the standard equation $3 \sigma / k$, where $\sigma$ is the standard deviation from the blank measurements and $k$ is the absolute value of the calibration curve at lower concentration [38], giving 2.35 and $1.01 \mu \mathrm{M}$ for $\mathbf{1}$ and $\mathbf{2}$, respectively. Noticeably, complexes $\mathbf{1}$ and $\mathbf{2}$ show comparative $\mathrm{K}_{\mathrm{sv}}$ with some previously reported complexes toward the detection of $\mathrm{Fe}^{3+}$ ions in aqueous phase solution (Table S2). The recyclability test showed no significant differences in the PXRD patterns (Figure S21) and the luminescence intensities (Figure S22) for five regeneration cycles, indicating the reusability and demonstrating that the quenching effect was not due to the structural decomposition of $\mathbf{1}$ and $\mathbf{2}$ upon the interactions with the $\mathrm{Fe}^{3+}$ ions. 


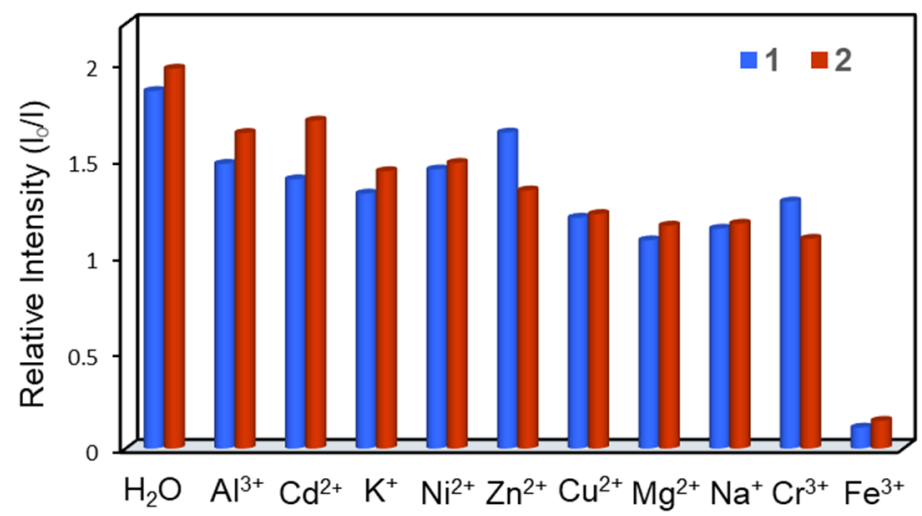

(a)
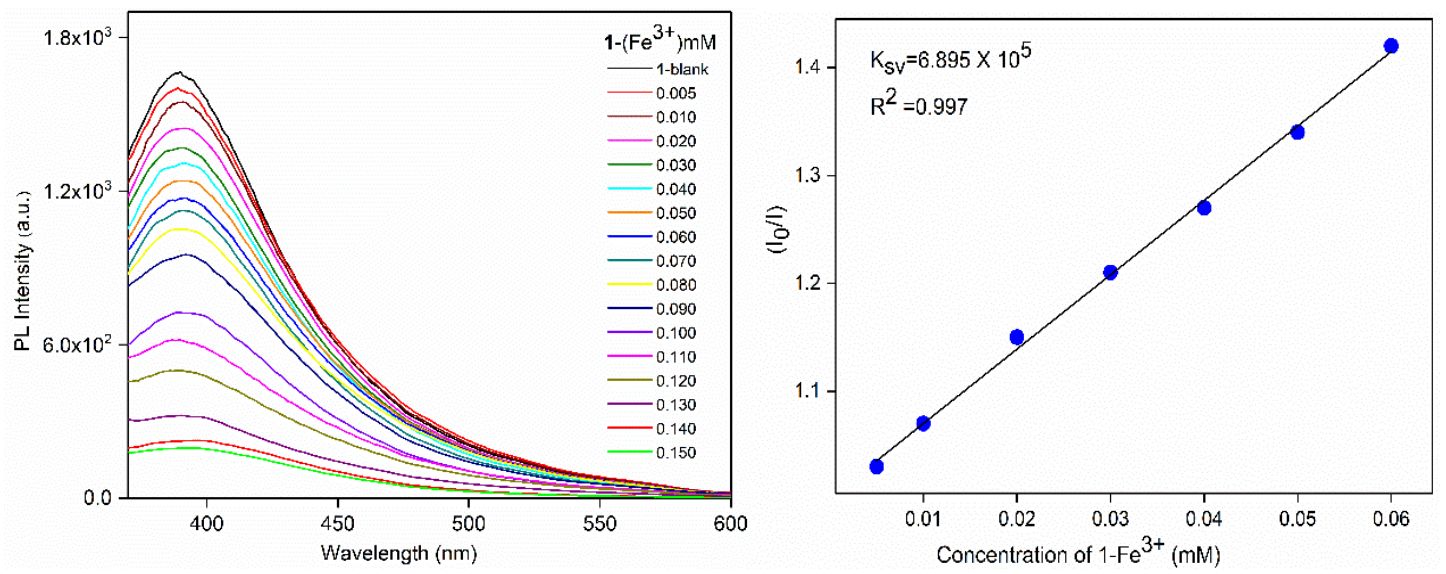

(b)
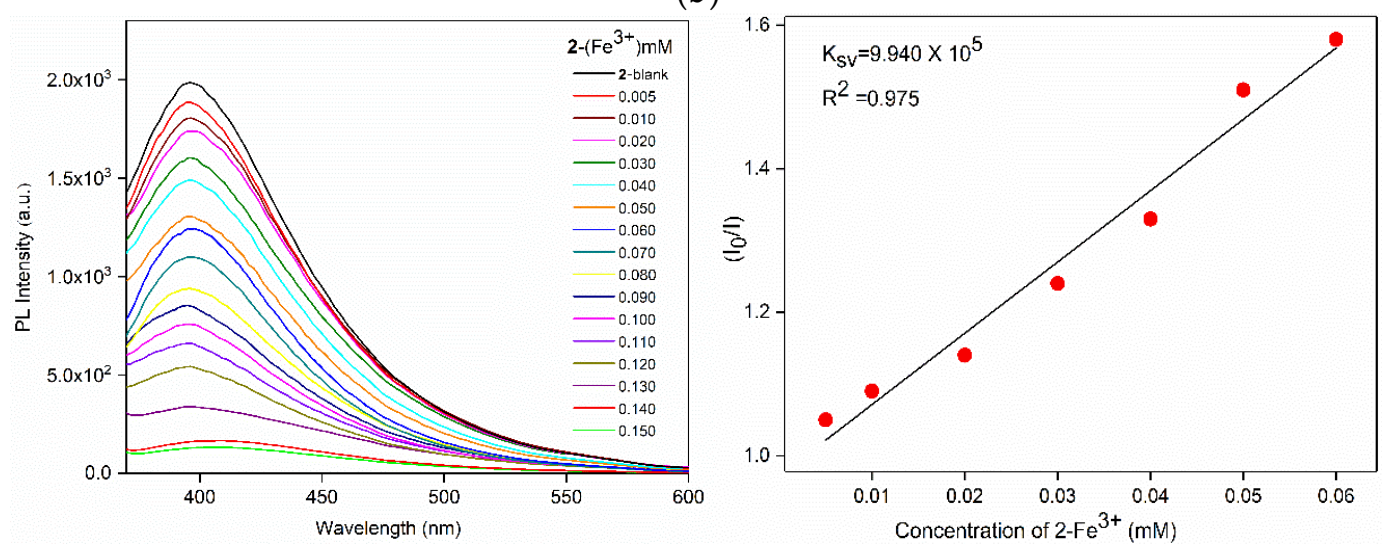

(c)

Figure 5. (a) Bar diagrams showing the relative emission intensities of $\mathbf{1}$ and $\mathbf{2}$ in various metal ions. Emission spectra of the activated (b) 1 and (c) 2 at various concentrations of $\mathrm{Fe}^{3+}$ (left), and the Stern-Volmer (sv) plot of $\mathrm{I}_{0} / \mathrm{I}_{\text {versus Fe }}{ }^{3+}$ concentration (right).

Several mechanisms for luminescence quenching such as framework collapse, cation exchange, and interactions between the incoming metal ion and the organic linker that result in competitive absorption of the excited energies of the sensed metal ion and the host $\mathrm{CPs}$, have been suggested [39]. As mentioned above, by comparing the PXRD patterns and luminescence intensities, the framework collapse can be ruled out. The interactions between $\mathrm{Fe}^{3+}$ ions and complexes $\mathbf{1}$ and $\mathbf{2}$ through the amide carbonyl oxygen atoms may thus lead to the luminescence quenching [40]. The UV-vis absorption spectrum of $\mathrm{Fe}^{3+}$ in aqueous solution and the corresponding excitation and emission spectra of complexes $\mathbf{1}$ and 2 are shown in Figure S23. Partial overlaps between the absorption spectrum of $\mathrm{Fe}^{3+}$ ion 
and the excitation spectra of complexes $\mathbf{1}$ and $\mathbf{2}$ are observed, indicating that the excitation energies of $\mathbf{1}$ and $\mathbf{2}$ can be partially absorbed by the $\mathrm{Fe}^{3+}$ ions, and the luminescence quenching can most probably be ascribed to competitive energy absorption [39].

\section{Conclusions}

Three eight-fold interpenetrated 3D CPs with the $\left(6^{6}\right)$-dia topology have been successfully prepared by using angular $\mathbf{L}$ and the linear dicarboxylic acid 1,4- $\mathrm{H}_{2} \mathrm{NDC}$. The $\mathrm{Zn}(\mathrm{II})$, $\mathrm{Cd}(\mathrm{II})$ and $\mathrm{Co}(\mathrm{II})$ metal centers of 1-3 adopt the distorted tetrahedral, pentagonal bipyramidal and octahedral/square pyramidal geometries, respectively, resulting in different coordination modes for the 1,4-NDC ${ }^{2-}$ ligands and indicating that the structural topology is not subject to the metal geometry. Their structural stabilities are assessed particularly in the aqueous environments, revealing that complexes 1 and 2 with close-shell $\mathrm{Zn}$ (II) and $\mathrm{Cd}(\mathrm{II})$ ions are much more stable than 3 with the open-shell $\mathrm{Co}$ (II) ion. The surface areas and pore structures of $\mathbf{1}$ and $\mathbf{2}$ were observed via $\mathrm{CO}_{2}$ gas sorption measurements and the activated samples of $\mathbf{1}$ and $\mathbf{2}$ explored by emission spectra and PXRD patterns demonstrate efficient detection of mesitylene and $\mathrm{Fe}^{3+}$ ions with high selectivity and recyclability. This investigation oversees the sensing properties of the highly entangled bpba-based CPs toward VOCs and metal ions.

Supplementary Materials: The following are available online at https://www.mdpi.com/article/10 .3390/polym13183018/s1. FT-IR spectra for 1-3 (Figure S1). PXRD patterns for 1-3 (Figures S2-S4). TGA curves for 1-3 (Figure S5). $\mathrm{CO}_{2}$ sorption isotherms of $\mathbf{1}$ and $\mathbf{2}$ (Figures S11-S13). Emission spectra for 1 and 2 (Figures S14 and S15). Sensing properties of reported compounds toward various aromatic VOCs (Table S1). Sensing properties of reported compounds toward $\mathrm{Fe}^{3+}$ ions (Table S2). Crystallographic data for 1-3 have been deposited with the Cambridge Crystallographic Data Centre, CCDC No. 2100027-2100029.

Author Contributions: Investigation, V.L. and Y.-T.L.; data curation, X.-K.Y. and M.G.; supervision, C.-H.L. and J.-D.C. All authors have read and agreed to the published version of the manuscript.

Funding: This research was funded by the Ministry of Science and Technology, Taiwan: MOST 109-2113-M-033-009.

Acknowledgments: We are grateful to the Ministry of Science and Technology of the Republic of China for their support.

Conflicts of Interest: The authors declare no conflict of interest.

\section{References}

1. Lustig, W.P.; Mukherjee, S.; Rudd, N.D.; Desai, A.V.; Li, J.; Ghosh, S.K. Metal-organic frameworks: Functional luminescent and photonic materials for sensing applications. Chem. Soc. Rev. 2017, 46, 3242-3285. [CrossRef]

2. Li, B.; Wen, H.-M.; Cui, Y.; Zhou, W.; Qian, G.; Chen, B. Emerging Multifunctional Metal-Organic Framework Materials. Adv. Mater. 2016, 28, 8819-8860. [CrossRef] [PubMed]

3. Pamela, B.S.; Chen, H.-T.; Lin, C.-H. De novo synthesis and particle size control of iron metal organic framework for diclofenac drug delivery. Microporous Mesoporous Mater. 2020, 309, 110495.

4. Ma, L.; Abney, C.; Lin, W. Enantioselective catalysis with homochiral metal-organic frameworks. Chem. Soc. Rev. 2009, 38, 1248-1256. [CrossRef] [PubMed]

5. Zhou, Y.-C.; Dong, W.-W.; Jiang, M.-Y.; Wu, Y.-P.; Li, D.-S.; Tian, Z.-F.; Zhao, J. A new 3D 8-fold interpenetrating $6^{6}$-dia topological Co-MOF: Syntheses, crystal structure, magnetic properties and electrocatalytic hydrogen evolution reaction. J. Solid-State Chem. 2019, 279, 120929. [CrossRef]

6. Du, M.; Jiang, X.-J.; Zhao, X.-J. Direction of unusual mixed-ligand metal-organic frameworks: A new type of 3-D polythreading involving 1-D and 2-D structural motifs and a 2-fold interpenetrating porous network. Chem. Commun. 2005, 44, 5521-5523. [CrossRef]

7. Yang, J.; Ma, J.-F.; Liu, Y.-Y.; Ma, J.-C.; Batten, S.R. A series of Lead (II) Complexes with $\pi-\pi$ Stackings: Structural Diversities by Varying the Ligands. Cryst. Growth Des. 2009, 9, 1894-1911. [CrossRef]

8. Carlucci, L.; Ciani, G.; Proserpio, D.M. Polycatenation, polythreading and polyknotting in coordination network chemistry. Coord. Chem. Rev. 2003, 246, 247-289. [CrossRef] 
9. Hsu, C.-H.; Huang, W.-C.; Yang, X.-K.; Yang, C.-T.; Chhetri, P.M.; Chen, J.-D. Entanglement and irreversible structural transformation in Co (II) Coordination Polymers Based on Isomeric Bis-pyridyl-bis-amide Ligands. Cryst. Growth Des. 2019, 19, 1728-1737. [CrossRef]

10. Wu, T.-T.; Hsu, W.; Yang, X.-K.; He, H.-Y.; Chen, J.-D. Entanglement in Co (II) coordination networks: Polycatenation from single net to 2-fold and 3-fold interpenetrated nets. CrystEngComm 2015, 17, 916-924. [CrossRef]

11. Liu, Y.-F.; Hu, J.-H.; Lee, W.-T.; Yang, X.-K.; Chen, J.-D. Structural Transformations of Cobalt(II) Coordination Polymers Constructed from $N, N^{\prime}$-Di-3-pyridyladipoamide and Tetracarboxylic Acids: Disentanglement upon Water Coordination. Cryst. Growth Des. 2020, 20, 7211-7218. [CrossRef]

12. Hsu, Y.-F.; Lin, C.-H.; Chen, J.-D.; Wang, J.-C. A Novel Interpenetrating Diamondoid Network from Self-Assembly of N,N'-Di(4pyridyl)adipoamide and Copper Sulfate: An Unusual 12-Fold, [6 + 6] Mode. Cryst. Growth Des. 2008, 8, 1094-1096. [CrossRef]

13. Cheng, J.-J.; Chang, Y.-T.; Wu, C.-J.; Hsu, Y.-F.; Lin, C.-H.; Proserpio, D.M.; Chen, J.-D. Highly interpenetrated diamondoid nets of $\mathrm{Zn}(\mathrm{II})$ and $\mathrm{Cd}(\mathrm{II})$ coordination networks from mixed ligands. CrystEngComm 2012, 14, 537-543. [CrossRef]

14. Kumar, P.; Deep, A.; Kim, K.-H.; Brown, R.J. Coordination polymers: Opportunities and challenges for monitoring volatile organic compounds. Prog. Polym. Sci. 2015, 45, 102-118. [CrossRef]

15. Ganguly, S.; Mukherjee, S.; Dastidar, P. Single-Crystal-to-Single-Crystal Breathing and Guest Exchange in Co(II) Metal-Organic Frameworks. Cryst. Growth Des. 2016, 16, 5247-5259. [CrossRef]

16. Bruker AXS Inc. APEX2, V2008.6, SADABS V2008/1, SAINT V7.60A, SHELXTL V6.14; Bruker AXS Inc.: Madison, WI, USA, 2008.

17. Sheldrick, G.M. A short history of SHELX. Acta Crystallogr. 2008, A64, 112-122. [CrossRef] [PubMed]

18. Blatov, V.A.; Shevchenko, A.P.; Proserpio, D.M. Applied Topological Analysis of Crystal Structures with the Program Package ToposPro. Cryst. Growth Des. 2014, 14, 3576-3586. [CrossRef]

19. Thapa, K.B.; Chen, J.-D. Crystal engineering of coordination polymers containing flexible bis-pyridyl-bis-amide ligands. CrystEngComm 2015, 17, 4611-4626. [CrossRef]

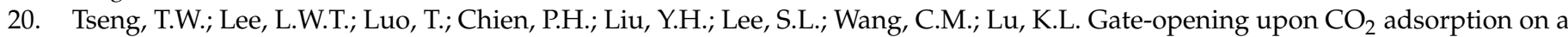
metal-organic framework that mimics a natural stimuli-response system. Dalton Trans. 2017, 46, 14728-14732. [CrossRef]

21. Lee, C.-H.; Huang, H.-Y.; Liu, Y.-H.; Luo, T.-T.; Lee, G.-H.; Peng, S.-M.; Jiang, J.-C.; Chao, I.; Lu, K.-L. Cooperative Effect of Unsheltered Amide Groups on $\mathrm{CO}_{2}$ Adsorption Inside Open-Ended Channels of a Zinc(II)-Organic Framework. Inorg. Chem. 2013, 52, 3962-3968. [CrossRef]

22. Yan, Y.; Peng, D.; Ma, J.-F.; Kan, W.-Q.; Liu, B.; Yang, J. A Series of Metal-Organic Frameworks Based on Different Salicylic Derivatives and 1,1'-(1,4- Butanediyl)bis(imidazole) Ligand: Syntheses, Structures, and Luminescent Properties. Cryst. Growth Des. 2011, 11, 5540-5553.

23. Niu, D.; Yang, J.; Guo, J.; Kan, W.-Q.; Song, S.-Y.; Du, P.; Ma, J.-F. Syntheses, Structures, and Photoluminescent Properties of 12 New Metal-Organic Frameworks Constructed by a Flexible Dicarboxylate and Various N-Donor Ligands. Cryst. Growth Des. 2012, 12, 2397-2410. [CrossRef]

24. Sun, D.; Yan, Z.-H.; Blatov, V.A.; Wang, L.; Sun, D.-F. Syntheses, Topological Structures, and Photoluminescences of Six New $\mathrm{Zn}$ (II) Coordination Polymers Based on Mixed Tripodal Imidazole Ligand and Varied Polycarboxylates. Cryst. Growth Des. 2013, 13, 1277-1289. [CrossRef]

25. Yang, J.-X.; Xin, Z.; Qin, Y.-Y.; Yao, Y.-G. N-Donor Auxiliary Ligand Influence on the Coordination Mode Variations of V- Shaped Triazole Dicarboxylic Acid Ligand Affording Seven New Luminescent Zn(II) Compounds with Variable Structural Motifs. Cryst. Growth Des. 2020, 20, 6366-6381. [CrossRef]

26. Gong, Y.; Li, J.; Qin, J.B.; Wu, T.; Cao, R.; Li, J.H. Metal(II) Coordination Polymers Derived from Bis-pyridyl-bis-amide Ligands and Carboxylates: Syntheses, Topological Structures, and Photoluminescence Properties. Cryst. Growth Des. 2011, 11, 1662-1674. [CrossRef]

27. Das, P.; Mandal, S.K. A dual-functionalized, luminescent and highly crystalline covalent organic framework: Molecular decoding strategies for VOCs and ultrafast TNP sensing. J. Mater. Chem. A. 2018, 6, 16246-16256. [CrossRef]

28. Parmar, B.; Bisht, K.K.; Rachuri, Y.; Suresh, E. Zn(ii)/Cd(ii) based mixed ligand coordination polymers as fluorosensors for aqueous phase detection of hazardous pollutants. Inorg. Chem. Front. 2020, 7, 1082-1107. [CrossRef]

29. Chang, Y.-T.; Lo, S.-H.; Lin, C.-H.; Hung, L.-I.; Wang, S.-L. Indium Phosphite-Based Porous Solids Exhibiting Organic Sensing and a Facile Route to Superhydrophobicity. Chem. Eur. J. 2018, 24, 12474-12479. [CrossRef]

30. Rani, P.; Gauri; Husain, A.; Bhasin, K.K.; Kumar, K. A Doubly Interpenetrated Cu(II) Metal-Organic Framework for Selective Molecular Recognition of Nitroaromatics. Cryst. Growth Des. 2020, 20, 7141-7151. [CrossRef]

31. Chen, J.-K.; Yang, S.-M.; Li, B.-H.; Lin, C.-H.; Lee, S. Fluorescence Quenching Investigation of Methyl Red Adsorption on Aluminum-Based Metal-Organic Frameworks. Langmuir 2018, 34, 1441-1446. [CrossRef]

32. Das, D.; Biradha, K. Luminescent Coordination Polymers of Naphthalene Based Diamide with Rigid and Flexible Dicarboxylates: Sensing of Nitro Explosives, Fe (III) Ion, and Dyes. Cryst. Growth Des. 2018, 18, 3683-3692. [CrossRef]

33. Shi, Y.-S.; Qiang, Y.; Zhang, J.-W.; Cui, G.-H. Four dual-functional luminescent Zn(ii)-MOFs based on 1,2,4,5-benzenetetracarboxylic acid with pyridylbenzimidazole ligands for detection of iron(iii) ions and acetylacetone. CrystEngComm 2021, 23, 1604-1615. [CrossRef] 
34. Zhang, M.; Feng, G.; Song, Z.; Zhou, Y.-P.; Chao, H.-Y.; Yuan, D.; Tan, T.T.Y.; Guo, Z.; Hu, Z.; Tang, B.Z.; et al. Two-Dimensional Metal-Organic Framework with Wide Channels and Responsive Turn-On Fluorescence for the Chemical Sensing of Volatile Organic Compounds. J. Am. Chem. Soc. 2014, 136, 7241-7244. [CrossRef] [PubMed]

35. Zhang, J.; Wang, J.; Long, S.; Peh, S.B.; Dong, J.; Wang, Y.; Karmakar, A.; Yuan, Y.D.; Cheng, Y.; Zhao, D. Luminescent Metal-Organic Frameworks for the Detection and Discrimination of o-Xylene from Xylene Isomers. Inorg. Chem. 2018, 57, 13631-13639. [CrossRef]

36. Liu, M.; Wei, Y.; Ou, Q.; Yu, P.; Wang, G.; Duan, Y.; Geng, H.; Peng, Q.; Shuai, Z.; Liao, Y. Molecular Design Strategy for Simultaneously Strong Luminescence and High Mobility: Multichannel CH- $\pi$ Interaction. J. Phys. Chem. Lett. 2021, 12, 938-946. [CrossRef] [PubMed]

37. Ge, F.-Y.; Sun, G.-H.; Lei, M.; Ren, S.-S.; Zheng, H.-G. Four New Luminescent Metal-Organic Frameworks as Multifunctional Sensors for Detecting $\mathrm{Fe}^{3+}, \mathrm{Cr}_{2} \mathrm{O}_{7}{ }^{2-}$ and Nitromethane. Cryst. Growth Des. 2020, 20, 1898-1904. [CrossRef]

38. Zhang, S.-H.; Zhang, S.-Y.; Li, J.-R.; Huang, Z.-Q.; Jing, Y.; Yue, K.-F.; Wang, Y.-Y. Rational synthesis of an ultra-stable Zn(ii) coordination polymer based on a new tripodal pyrazole ligand for the highly sensitive and selective detection of $\mathrm{Fe}^{3+}$ and $\mathrm{Cr}_{2} \mathrm{O}_{7}{ }^{2-}$ in aqueous media. Dalton Trans. 2020, 49, 11201-11208. [CrossRef] [PubMed]

39. Pamei, M.; Puzari, A. Luminescent transition metal-organic frameworks: An emerging sensor for detecting biologically essential metal ions. Nano-Struct. Nano-Objects 2019, 19, 100364. [CrossRef]

40. Yang, X.-K.; Lee, W.-T.; Hu, J.-H.; Chen, J.-D. Zn(II) and Cd(II) coordination polymers with a new angular bis-pyridyl-bis-amide: Synthesis, structures and sensing properties. CrystEngComm 2021, 23, 4486-4493. [CrossRef] 